\title{
Modification of thin films induced by slow heavy ions analysed with PIXE and SRIM*
}

\author{
Małgorzata Antoszewska-Moneta ${ }^{a}$, Romuald Brzozowski, and Marek Moneta \\ Uniwersytet Łódzki, Wydział Fizyki i Informatyki Stosowanej, Pomorska 149, 90-236 Łódź, Poland \\ Received 27 August 2014 / Received in final form 7 December 2014 \\ Published online 17 March 2015 \\ (c) The Author(s) 2015. This article is published with open access at Springerlink.com
}

\begin{abstract}
In the present work the particle induced X-rays (PIXE) emitted during interaction of inert and active slow heavy (HI) ions with specially prepared thin films were measured. Kinematics of the interaction was simulated numerically with SRIM in grazing incident-exit angle geometry and in time sequence in order to determine dynamics of formation of the subsurface region damaged through implantation, sputtering and interface mixing. It was shown that the structure and composition of films and surfaces are not stable against HI irradiation due to preferential sputtering and implantation of ions and recoils and that dynamics of such a modification can be in-situ monitored with PIXE and analyzed with SRIM.
\end{abstract}

\section{Introduction}

The impact of heavy ions of natural or artificial origin on the surface of multicomponent material like metallic thin films or organic cell membrane results in implantation of beam ions, preferential sputtering of surface elements and selective implantation of recoils, thus changing primary composition of the surface, creation of ion tracks and production of radicals [1-3]. Extensive kinematic mixing of the surface and interfaces combined with local thermal heating caused by energy deposited in the surface as the heavy ion (HI) slows down, can be observed [4]. Also, chemical reactions with biological consequences are expected, if chemically active or even toxic ions are used. These phenomena determine structural transformations of the materials and influence their electric and magnetic, as well as thermal properties [5-8].

The particle induced X-rays emission (PIXE) is one of the methods which can give an insight into these processes $[9,10]$. It is based on the analysis of characteristic $\mathrm{X}$-rays emitted during the impact of HI on the surface. They provide information on fundamental atomic excitation and subsequent recombination processes and give practical information on elemental composition and dynamics of restructuring of the films and subsurface region measured during irradiation [11]. We use PIXE accompanied with extensive simulations to determine dynamics of a composition change of multicomponent thin film or organic layers subjected to prolonged irradiation with inert HI.

\footnotetext{
* Contribution to the Topical Issue "Elementary Processes with Atoms and Molecules in Isolated and Aggregated States", edited by Friedrich Aumayr, Bratislav Marinkovic, Stefan Matejcik, John Tanis and Kurt H. Becker.

a e-mail: m_ateno@interia.pl
}

Since HI impact is a destructive event, the X-rays spectra emitted by $\mathrm{Fe} / \mathrm{Si}$ and $\mathrm{Fe} / \mathrm{Cu} / \mathrm{Si}$ thin films during the irradiation with Ar ions of the energy $220 \mathrm{keV}$ were measured in time sequence in order to determine the stability of the films against HI sputtering, interface mixing, implantation and creation of recoils and cascades.

\section{Experimental set-up}

The experimental setup was described elsewhere [11]. In brief it is based on $\mathrm{He} / \mathrm{N} / \mathrm{Ar} / \mathrm{Xe}$ ions beams from $300 \mathrm{kV}$ Cockroft-Walton multiplier with vacuum in reaction chamber better than $0.1 \mathrm{mPa}$. Thin films were evaporated from Knudsen cell on Si surface cleaned in $\mathrm{HF}$ at a high temperature. The targets were mounted on a two axis goniometer in double alignment geometry: the incident grazing angle was fixed at $\phi_{i n} \leq 5^{\circ}$ and the exit grazing angle was fixed at $\phi_{\text {out }} \leq 0.5^{\circ}$ after preliminary measurements minimizing the signal from the Si background. PIXE spectra were measured by a SDD (Si drift detector) spectrometer (fwhm 120 eV@6.4 keV) placed behind a $25 \mu$ m kapton window.

\section{Results and discussion}

\subsection{Stability of thin films of $\mathrm{Fe} / \mathrm{Cu} / \mathrm{Si}$ and $\mathrm{Fe} / \mathrm{Si}$ with PIXE induced by Ar}

In order to get some insight into the ion scattering process, the present experimental arrangement with 50-250 keV Ar ion beam impact on $\mathrm{Fe} / \mathrm{Cu} / \mathrm{Si}$ trilayer and on $\mathrm{Fe} / \mathrm{Si}$ bilayer at $5^{\circ}$ angles of incidence (and other appropriate initial parameters) were simulated with SRIM [4] and presented in Figure 1. They reveal that emission of atomic 


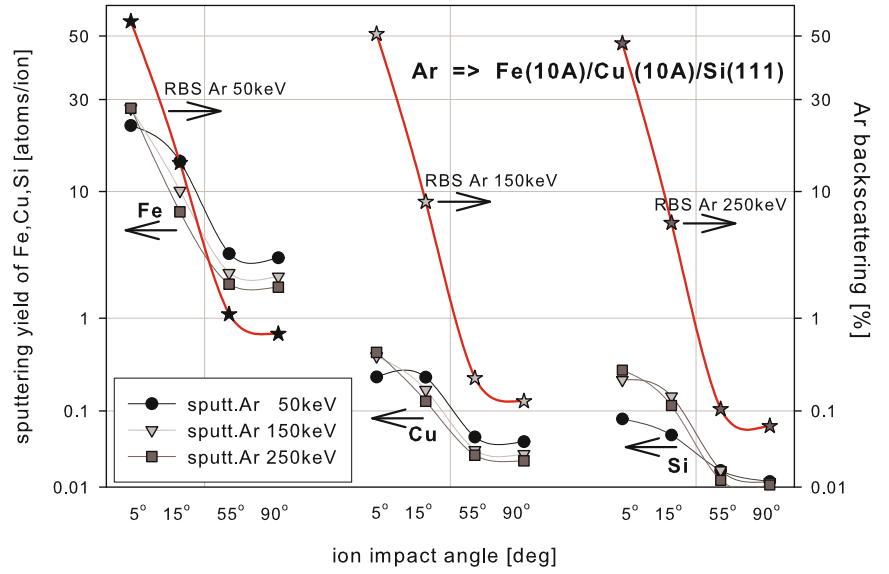

Fig. 1. Erosion of the surface composed of thin films subjected to $\mathrm{HI}$ irradiation as sputtering yield of $\mathrm{Fe}(10 \AA) / \mathrm{Cu}(10 \AA) /$ $\mathrm{Si}$ (111) trilayer under impact of 50-250 keV Ar ions at different incident angles - simulation with SRIM [4]. Also, the reflection of the ion beam as backscattering (RBS) of incident Ar ions is shown as a function of initial energy and angle of impact on the surface.

species from the irradiated surface is strongly energy and incident angle dependent. Also reflection of incident ions from the surface shows the similar angular dependence. In the grazing incidence geometry $\phi_{i n}<5^{\circ}$, an $\mathrm{Ar}$ ion can sputter about $30 \mathrm{Fe}$ atoms and about 50\% incident $\mathrm{Ar}$ ions fluence is scattered back from the surface, whereas the remaining part is implanted. If an incident fluence of $10^{15} \mathrm{Ar} / \mathrm{cm}^{2}$ at $\phi_{\text {in }}=5^{\circ}$ is assumed, a $3 \mathrm{~nm}$ thick layer will be sputtered from the Fe surface. This should be compared with penetration depth of $40 \mathrm{~nm}$ and projected range of $100 \mathrm{~nm}$ of Ar ions in Fe. Before backscattering or stopping the ions suffer multiple collisions losing energy to electrons and creating vacancies and cascades. The $\mathrm{Cu}$ film and Si substrate are expected to be sputtered at a negligible yield of $0.45 \mathrm{Cu} / \mathrm{Ar}(\mathrm{Cu}$ atoms per incident $\mathrm{Ar}$ ion) and $0.35 \mathrm{Si} / \mathrm{Ar}$ respectively, thus being completely screened by Fe film.

In SRIM-simulation of irradiation of $\mathrm{Fe}(10 \AA) /$ $\mathrm{Cu}(10 \AA) / \mathrm{Si}$ trilayer with $220 \mathrm{keV}$ Ar ions at the grazing incidence of $5^{\circ}$ we observe in Figure 2 depth distributions: of the energy absorbed by $\mathrm{Fe}, \mathrm{Cu}$ and $\mathrm{Si}$ recoils in Figure 2a, of these recoils themselves - in Figure 2b, of vacancies left behind these recoils - in Figure 2c, and of the energy on ionisation lost by the ions and recoils in Figure 2d. It can be seen that ions backscattering, recoils sputtering, transfer of energy, creation of vacancies and recoils cascades are localised in the surface itself and dominate in the first thin film. The depth distributions of $\mathrm{Fe}, \mathrm{Cu}$ and $\mathrm{Si}$ recoils prove extensive interface mixing and deep homogenization of the irradiated trilayer through implantation of recoils. The part of incident ions which is not backscattered travel in the surface layer, initialize cascades and excite atoms in the topmost thin films. That means that in this geometry there is measured the PIXE radiation which is emitted mainly from the excited target atoms leaving the surface and from the incident ions
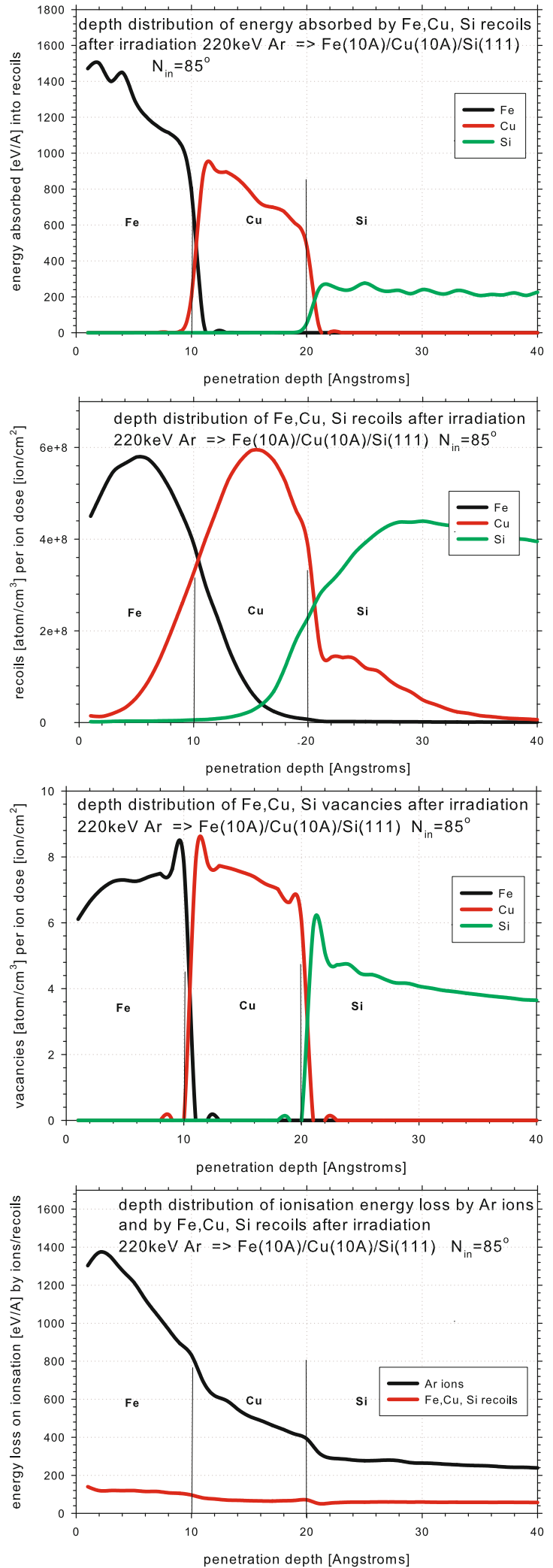

Fig. 2. From top to bottom respectively the depth distributions of: (a) the energy absorbed by recoils, (b) $\mathrm{Fe}, \mathrm{Cu}, \mathrm{Si}$ recoils, (c) vacancies, and (d) the energy loss by ions and recoils on ionisation in $\mathrm{Fe}(10 \AA) / \mathrm{Cu}(10 \AA) / \mathrm{Si}$ trilayer after irradiation with $220 \mathrm{keV} \mathrm{Ar}$ ions at the grazing incidence of $5^{\circ}$. Calculated with SRIM [4]. 


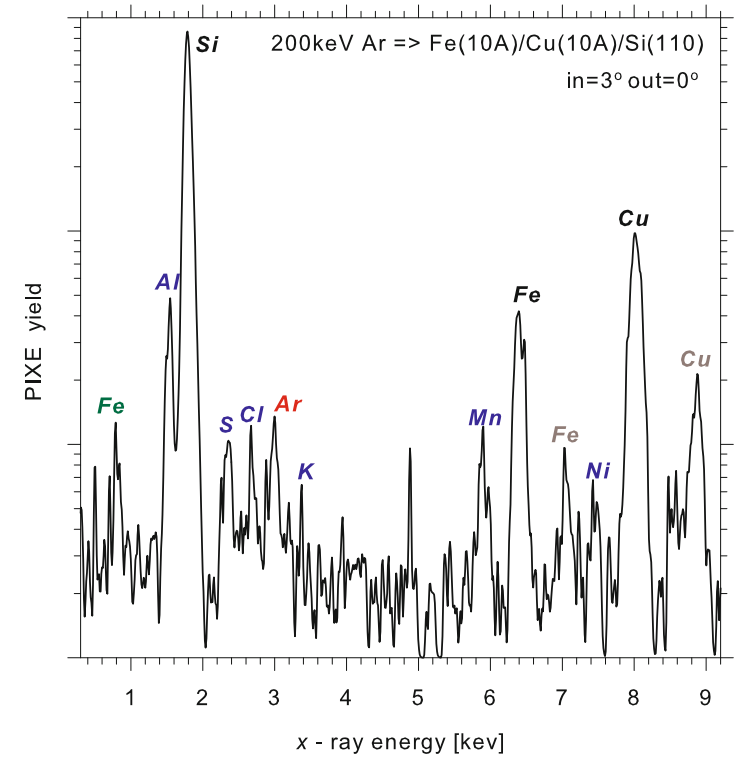

Fig. 3. PIXE spectrum induced during irradiation of $\mathrm{Fe}(10 \AA) / \mathrm{Cu}(10 \AA) / \mathrm{Si}(110)$ with $200 \mathrm{keV} \mathrm{Ar}^{6+}$. The implanted dose $3 \times 10^{12} \mathrm{Ar} / \mathrm{cm}^{2}$ corresponds to about $3.5 \mathrm{ppm}$ of Ar. Thin films were evaporated from Knudsen cell. Thickness measured with a quartz resonator. Angles $\phi_{i n}=3^{\circ}$ and $\phi_{\text {out }}=0^{\circ}$ are related to the surface. The SDD X-ray spectrometer with the resolution of $120 \mathrm{eV} / 6.4 \mathrm{keV}$ was used. Figure from [11].

backscattered in an excited state. Radiation from deep layers and substrate should be fairly suppressed.

An example of the PIXE spectrum with $\mathrm{Fe}, \mathrm{Cu}$ and $\mathrm{Si}$ K-shell X-rays emitted by trilayer $\mathrm{Fe}(10 \AA) / \mathrm{Cu}(10 \AA) /$ $\mathrm{Si}(110)$ during irradiation with Ar ions of the energy $200 \mathrm{keV}$ at $3 \times 10^{12} \mathrm{Ar} / \mathrm{cm}^{2}$, is shown in Figure 3 . The spectrum also contains K-shell signal from Ar which is accumulated during irradiation and signals from trace impurities S, Cl and elements contained in the environment $\mathrm{Mn}, \mathrm{Ni}$. The ions were directed at the incidence angle $\phi_{\text {in }}=3^{\circ}$ to the surface in order to have low penetration depth. Radiation was measured at the grazing exit angle in order to suppress the bremsstrahlung.

In order to determine stability of the films against $\mathrm{HI}$ sputtering and recoil implantation, again we used time sequence in measuring X-ray signals coming from the films or implanted elements and related them to the signal from Si base. The result of PIXE analysis for $200 \mathrm{keV}$ Ar impact on $\mathrm{Fe}(10 \AA) / \mathrm{Cu}(10 \AA) / \mathrm{Si}(110)$ is shown in Figure 4 . It can be seen that not only signals from $\mathrm{Fe}$ and $\mathrm{Cu}$ decrease by a few per cent but also the signal from Si loses intensity, whereas radiation from Ar increases proportionally to the implanted dose and becomes detectable at the concentration of a few ppm. That means that use of HI at this geometry enables X-ray characterisation of the film, despite the destructive consequences of HI impact.

Another detailed analysis of PIXE induced by Ar impact onto $\mathrm{Fe}(10 \mathrm{~nm}) / \mathrm{Si}(110)$ film is presented in Figure 5. The X-ray intensity from Ar increases monotonically and shortly becomes comparable with the decreasing signal

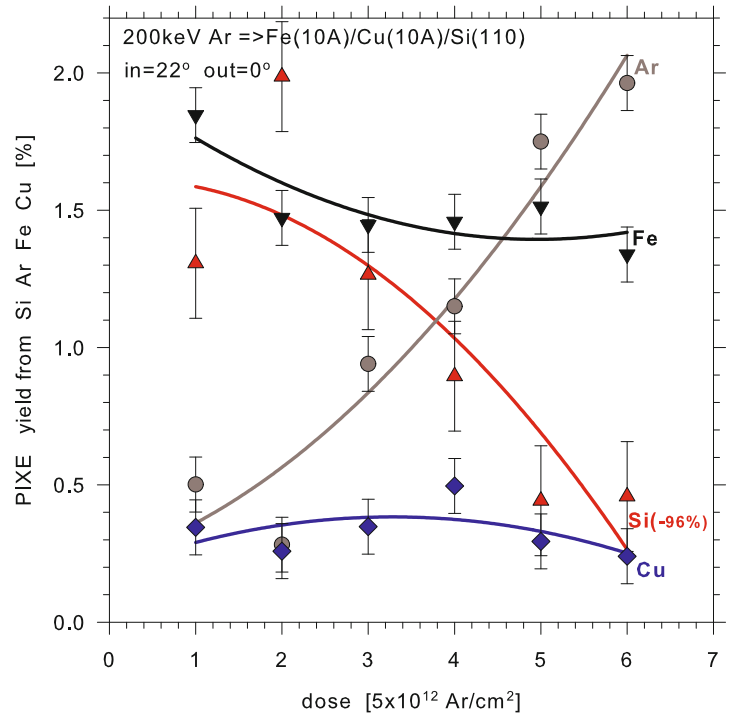

Fig. 4. Stability of $\mathrm{Fe}(10 \AA) / \mathrm{Cu}(10 \AA) / \mathrm{Si}(110)$ thin film against the dose of $200 \mathrm{keV}$ Ar beam at the grazing-exit geometry measured by signals from $\mathrm{Ar}, \mathrm{Fe}, \mathrm{Cu}$ and $\mathrm{Si}$ in the PIXE spectra shown in Figure 3. Angles $\phi_{\text {in }}=22^{\circ}$ and $\phi_{\text {out }}=0^{\circ}$ are related to the surface. Figure from [11].

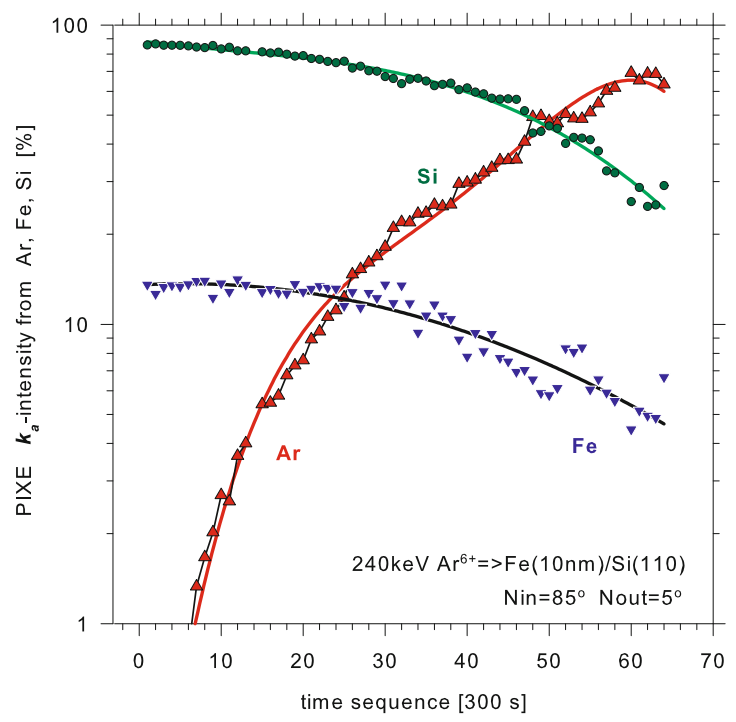

Fig. 5. Time sequence dependence of the intensity of radiation from $\mathrm{Fe}, \mathrm{Si}$ and $\mathrm{Ar}$ in the PIXE spectra during impact of $240 \mathrm{keV}$ Ar ions on $\mathrm{Fe}(10 \mathrm{~nm}) / \mathrm{Si}(110)$ film. The $300 \mathrm{~s}$ corresponds to an implanted dose of $10^{12} \mathrm{Ar} / \mathrm{cm}^{2}$. The sputtering yield $\mathrm{Y}=30 \mathrm{Fe} / \mathrm{Ar}$, the $\mathrm{Ar} \mathrm{RBS}=0.53$ [4]. The angles are related to the surface normal.

from Si. The Ar atoms which in this geometry are mainly RBS-scattered (50\%), tend to be uniformly distributed in the film with a slight density increase (up to $0.06 \%$ ) in the region of mixed $\mathrm{Fe} / \mathrm{Si}$ interface [4], thus intensifying radiation through molecular effect in symmetrical collisions. The declining radiation from Si substrate can be understood as an effect of absorption of the radiation by additional Ar component of the film. The decrease of the signal from $\mathrm{Fe}$ can be explained by intensive surface sputtering 
which at this geometry is $\mathrm{Y} \approx 30 \mathrm{Fe} / \mathrm{Ar}$, thus thinning the film at the speed of $1 \AA$ of Fe per $10^{12} \mathrm{Ar} / \mathrm{cm}^{2}$ dose which is illustrated in Figure 5.

\subsection{Stability of cellular membranes against $\mathrm{HI}$ irradiation analysed with SRIM}

Cellular membranes are composed mainly of light elements which emit soft X-rays, easily absorbed in the environment and hardly detectable even with top-quality SDD detectors, although recently used Si3N4 windows instead of Be windows allow detection of $\mathrm{X}$-rays from $\mathrm{O}$ and even $\mathrm{C}$. We assume that the basic processes such as ions and recoils implantation, preferential sputtering, vacancy production, energy transfer and many other characteristics calculated from SRIM are purely atomic phenomena and thus weakly dependent on the structure of the surface. Some conclusions about the atomic processes in organic materials can be drawn on the basis of comparison of atomic kinematics simulation (with SRIM) in these materials with simulation of the kinematics accompanied by X-rays measurements with especially prepared surfaces or thin films composed of heavier elements.

The major membrane lipids are phospholipids, fatty acid chains in the range of 16-18 carbons long; chains with fewer than 12 carbons cannot form a stable bilayer. Phospholipid chains are amphipathic molecules - one end, the head which has a negatively-charged (polar) region, while the remainder of the molecule, the tail, consists of two (nonpolar) long fatty acid chains. The phospholipids in cell membranes organize themselves into a bimolecular layer with the nonpolar fatty acid chains in the middle. The polar regions are oriented toward the membrane surfaces due to their attraction to the polar water molecules in the extracellular and cytosolic fluids. Properties of the membrane, analysed by an ion beam, are determined mainly by it composition, thickness and structure.

For the present simulations [4] of ion beam impact on the cellular membrane we accepted a model, shown in Figure 6, in which the membrane is composed of a double layer of phosphatidylcholine separating the cellular interior filled with water from the exterior of the cell, set as a diluted gas phase. Heads of the phospholipids are represented by structures: $\mathrm{H}_{18} \mathrm{C}_{10} \mathrm{~N}_{1} \mathrm{O}_{8} \mathrm{P}_{1}$, $\mathrm{H}_{11} \mathrm{C}_{8} \mathrm{~N}_{1} \mathrm{O}_{10} \mathrm{P}_{1}, \mathrm{H}_{12} \mathrm{C}_{7} \mathrm{~N}_{1} \mathrm{O}_{8} \mathrm{P}_{1}$ and $\mathrm{H}_{21} \mathrm{C}_{11} \mathrm{~N}_{2} \mathrm{O}_{5} \mathrm{P}_{1}$, respectively. Fatty tails of the molecules, composed of hydrogens and carbons in the proportion $\mathrm{C}_{32} \mathrm{H}_{64}$, which belong to palmitic and oleic acids, were arranged in an internal matrix of $6 \mathrm{~nm}$ thick placed between hydrophobic heads, each $1.5 \mathrm{~nm}$ thick. Ar ions of the energy $50-250 \mathrm{keV}$ were directed either at the grazing incidence or perpendicularly to the membrane surface and the basic characteristics were accumulated.

The sputtering efficiency of recoils from the selected regions of the cell membrane under impact of Ar ions of different energies at normal incidence is shown in Figure 7 . The regions of heads, legs and water forming the cell interior were separated. The sputtering of hydrogen is prevailing, which means that $\mathrm{H}$ atoms are subjected
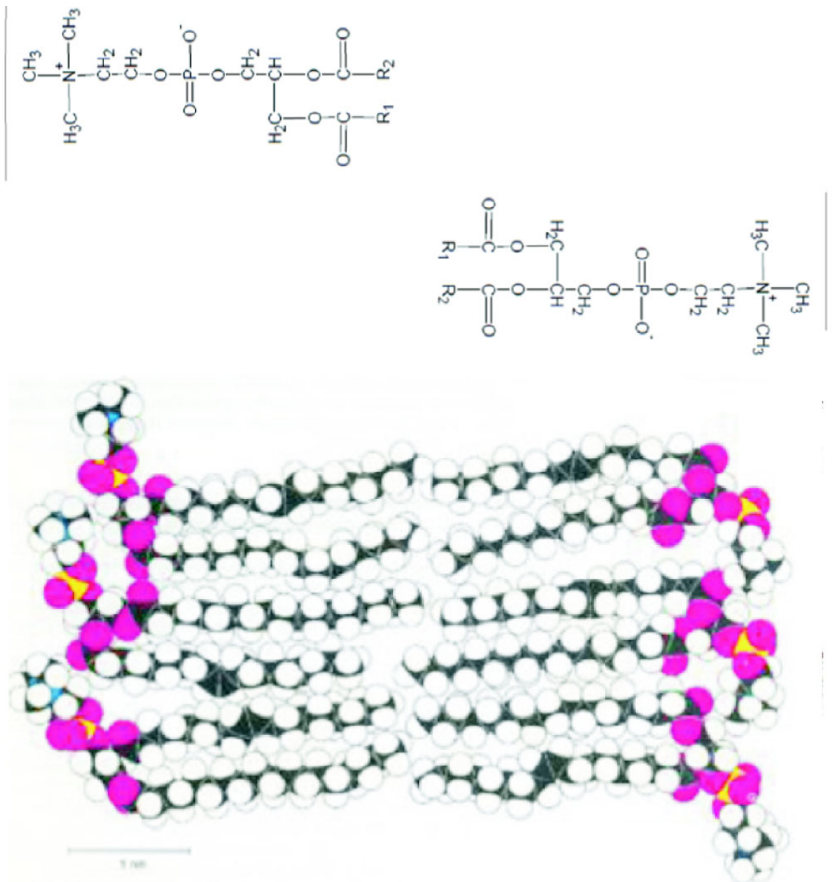

Fig. 6. Phosphatidylcholine and a schematic cross section of the cell wall. The red circle denotes the hydrophilic head consisting of a polar phosphoglycerol group and the dotted lines represent the hydrocarbon chains forming a tight hydrophobic barrier excluding water as well as polar or charged compounds.

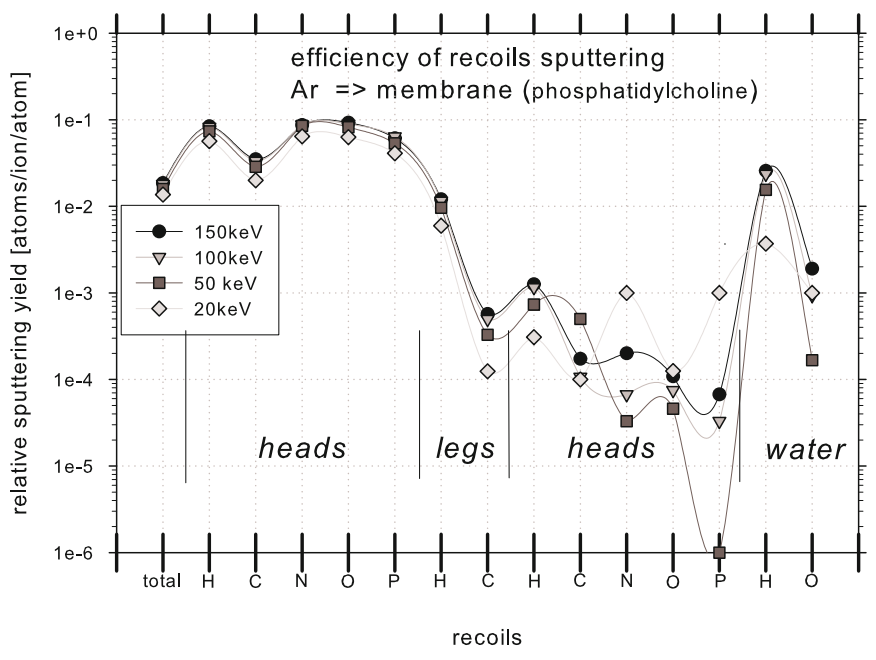

Fig. 7. Sputtering efficiency of recoils (in the chemical formula) from selected regions of the cell membrane under impact of $\mathrm{Ar}$ ions of different energies at normal incidence, calculated with SRIM. At the grazing angle incidence $\left(\phi_{i n}<5^{\circ}\right)$ the sputtering yield increases approximately 10 times.

to hard collisions, which can lead to ionisation and emission of X-rays due to radiative deexcitations. It can be also seen that oxygen from external heads exposed to ion beam, is an order of magnitude more effectively sputtered than $\mathrm{N}$ and $\mathrm{P}$ belonging to the same structure, and that this effect is approximately independent of ion energy. Atomic species from internal heads are sputtered and 

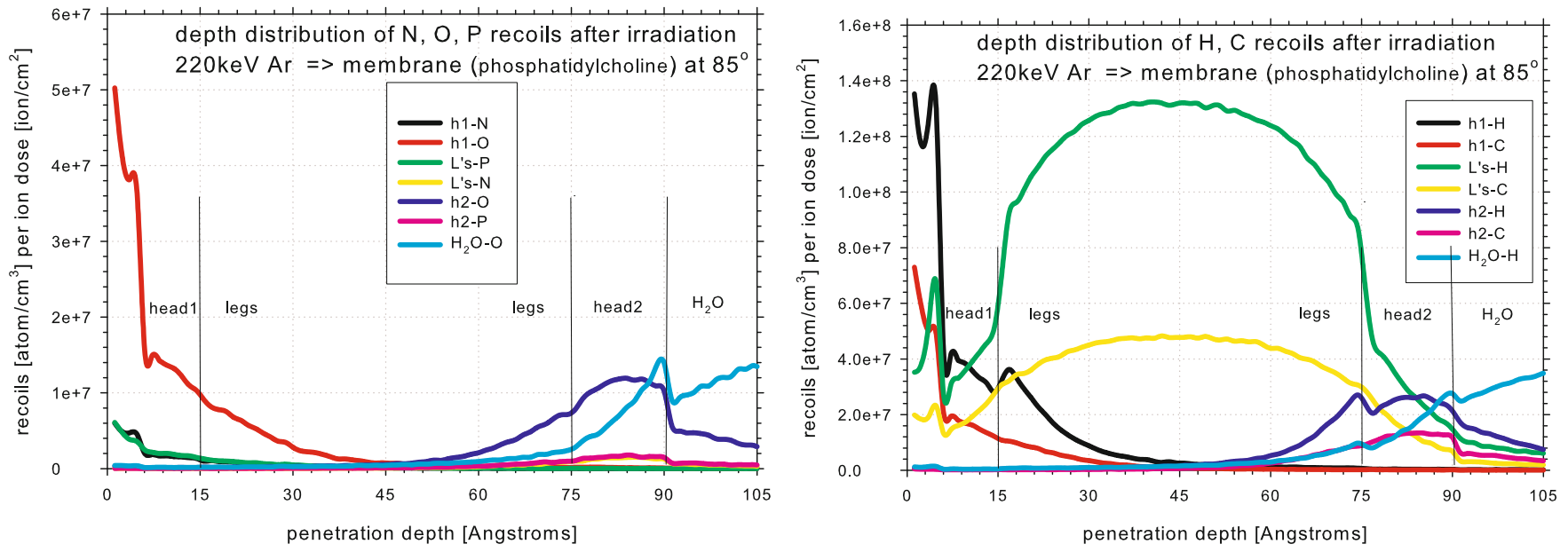

Fig. 8. SRIM-simulated depth distribution of recoils in specified parts of membrane composed of double-layered phosphatidylcholine after impact of $220 \mathrm{keV}$ Ar ion at grazing angle incidence $\left(\phi_{i n}<5^{\circ}\right)$ to the surface. The left figure displays distribution of $\mathrm{N}, \mathrm{O}$ and $\mathrm{P}$ recoils, whereas the right figure shows distribution of $\mathrm{H}$ and $\mathrm{C}$ recoils.
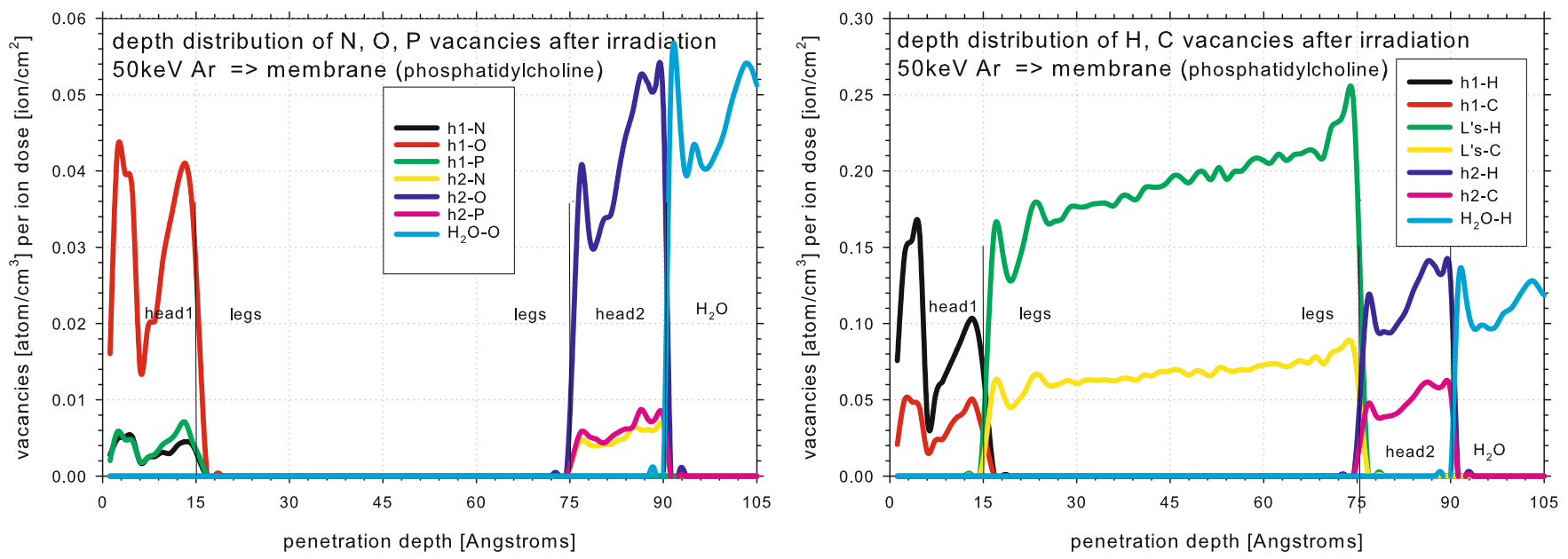

Fig. 9. SRIM-simulated depth distribution of vacancies formed in selected regions of the membrane composed of double-layered phosphatidylcholine after the impact of $50 \mathrm{keV}$ Ar ion perpendicularly to the surface. The left figure displays distribution of vacancies after $\mathrm{N}, \mathrm{O}$ and $\mathrm{P}$ atoms, whereas the right figure shows vacancies after $\mathrm{H}$ and $\mathrm{C}$ atoms.

excited $10^{3}$ times less effectively than these from external ones. The sputtering depends on incident angle and at grazing incidence $\left(\phi_{i n}<5^{\circ}\right)$ the sputtering yield increases approximately 10 times compared to normal incidence.

The depth distribution of recoils in indicated parts of membrane composed of phosphatidylcholine after impact of $220 \mathrm{keV}$ Ar ion at grazing angle incidence $\left(\phi_{i n}<5^{\circ}\right)$ to the surface is shown in Figure 8. The left figure displays distribution of $\mathrm{N}, \mathrm{O}$ and $\mathrm{P}$ atoms, whereas the right figure shows distribution of $\mathrm{H}$ and $\mathrm{C}$. A high concentration of $\mathrm{O}$ and $\mathrm{H}$ recoils, from the head exposed to beam can be found in this head with a maximum at the surface. A high density of $\mathrm{H}$ and $\mathrm{C}$ recoils coming from the legs can be spotted in the same region, but also in the head region. The main feature of these distributions is that they spread far over the initial boundaries showing extensive interface mixing, with migration of recoils over long distances of several ^'s.
The depth distribution of vacancies formed in the specified regions of the phosphatidylcholine membrane after the impact of $50 \mathrm{keV}$ Ar ion, directed perpendicularly to the surface, is shown in Figure 9. The left figure displays distribution of vacancies remained after $\mathrm{N}, \mathrm{O}$ and $\mathrm{P}$ atoms, whereas the right figure shows the distribution of vacancies after $\mathrm{H}$ and $\mathrm{C}$. The creation of vacancies is most intense for hydrogen from heads and legs, and also for oxygen from both heads. Oxygen vacancies form a double peak structure in depth distribution within heads, whereas hydrogen and carbon vacancies form increasing in depth density distribution within legs region.

The creation of vacancies in a molecule by $\mathrm{HI}$ and introduction of external recoiled atoms or implanted ions cause a dramatic change in the structure and composition of the irradiated object as well as in its chemical and biochemical functions. The transfer of energy is caused mainly through ionisation and electronic excitations so 

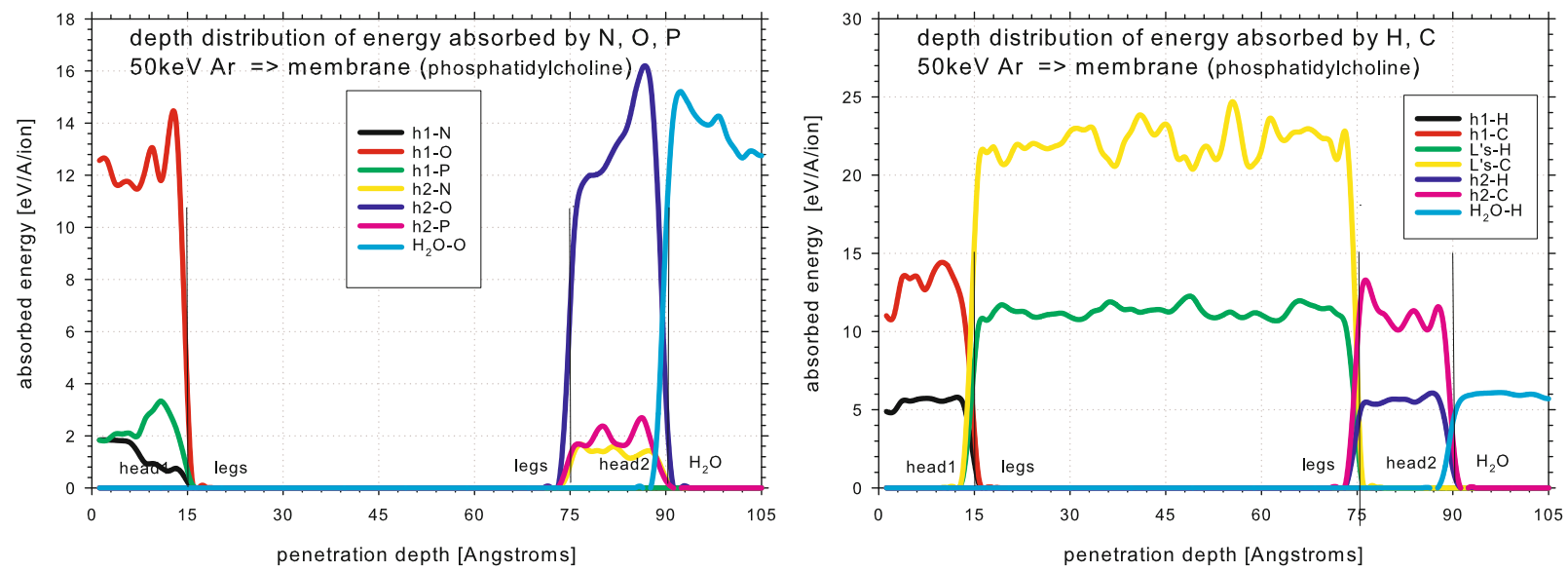

Fig. 10. Depth distribution of energy absorbed by N, O and P atoms (left) and by $\mathrm{H}$ and $\mathrm{C}$ (right) from the indicated parts of the membrane composed of a double-layered phosphatidylcholine after irradiation with $50 \mathrm{keV}$ Ar ions along normal to the surface. Simulated with SRIM.

distribution of the electronic energy loss shown in Figure 10 is correlated with the distribution of free radicals which exert an effect on chemical and biochemical performance of the irradiated object.

\section{Conclusions}

There was shown with the use of simulation with SRIM that the structure and composition of the surface is not stable against HI irradiation due to preferential sputtering, interface mixing and implantation of ions and recoils and that dynamics of such a modification can be quantitatively monitored by means of the PIXE measurements.

\section{References}

1. M. Toulemonde, C. Dufour, E. Paumier, Phys. Rev. B 46, 14362 (1992)

2. A.S. El-Said, R. Heller, W. Meissl, R. Ritter, S. Facsko, C. Lemell, B. Solleder, I.C. Gebeshuber, G. Betz, M. Toulemonde, W. Moller, J. Burgdorfer, F. Aumayr, Phys. Rev. Lett. 100, 237601 (2008)

3. B. Pawłowski, M. Moneta, Nucl. Instrum. Methods Phys. Res. B 297, 194 (2012)
4. J.F. Ziegler, J.P. Biersack, M.D. Ziegler, The Stopping and Range of Ions in Solids (2008), http://www. SRIM.org

5. G. Herzer, IEEE Trans. Magn. 26, 1397 (1990)

6. R. Brzozowski, M. Wasiak, H. Piekarski, P. Sovak, P. Uznański, M. Moneta, J. Alloys Compd. 470, 5 (2009)

7. M. Moneta, R. Brzozowski, M. Wasiak, P. Uznański, Nucl. Instrum. Methods Phys. Res. B 267, 411 (2009)

8. R. Brzozowski, M. Moneta, Nucl. Instrum. Methods Phys. Res. B 297, 208 (2012)

9. S.A.E. Johansson, J.L. Campbell, K.G. Malmqvist, Particle Induced X-ray Emission Spectrometry (PIXE) (Wiley, 1995)

10. Y. Mokuno, Y. Horino, A. Kinomura, A. Chayahara, N. Tsubouchi, K. Fujii, Nucl. Instrum. Methods Phys. Res. B 109, 573 (1996)

11. M. Antoszewska, R. Brzozowski, J. Balcerski, K. Dolecki, E. Frątczak, B. Pawowski, M. Moneta, Nucl. Instrum. Methods Phys. Res. B 310, 27 (2013)

Open Access This is an open access article distributed under the terms of the Creative Commons Attribution License (http://creativecommons.org/licenses/by/4.0), which permits unrestricted use, distribution, and reproduction in any medium, provided the original work is properly cited. 